\title{
Development of Flow-Through Polymeric Membrane Reactor for Liquid Phase Reactions: Experimental Investigation and Mathematical Modeling
}

\author{
Endalkachew Chanie Mengistie ${ }^{1}$ and Jean-François Lahitte ${ }^{2}$ \\ ${ }^{1}$ Bahir Dar Institute of Technology (BiT), Faculty of Chemical and Food Engineering, Bahir Dar University, 1920 Bahir Dar, Ethiopia \\ ${ }^{2}$ Laboratoire de Genie Chimique, Universite Paul Sabatier, 118 route de Narbonne, Toulouse, France
}

Correspondence should be addressed to Endalkachew Chanie Mengistie; endalk10@gmail.com

Received 3 August 2017; Accepted 7 November 2017; Published 29 November 2017

Academic Editor: Jose C. Merchuk

Copyright (C) 2017 Endalkachew Chanie Mengistie and Jean-François Lahitte. This is an open access article distributed under the Creative Commons Attribution License, which permits unrestricted use, distribution, and reproduction in any medium, provided the original work is properly cited.

\begin{abstract}
Incorporating metal nanoparticles into polymer membranes can endow the membranes with additional functions. This work explores the development of catalytic polymer membrane through synthesis of palladium nanoparticles based on the approaches of intermatrix synthesis (IMS) inside surface functionalized polyethersulfone (PES) membrane and its application to liquid phase reactions. Flat sheet PES membranes have been successfully modified via UV-induced graft polymerization of acrylic acid monomer. Palladium nanoparticles have been synthesized by chemical reduction of palladium precursor loaded on surface modified membranes, an approach to the design of membranes modified with nanomaterials. The catalytic performances of the nanoparticle incorporated membranes have been evaluated by the liquid phase reduction of $p$-nitrophenol using $\mathrm{NaBH}_{4}$ as a reductant in flow-through membrane reactor configuration. The nanocomposite membranes containing palladium nanoparticles were catalytically efficient in achieving a nearly $100 \%$ conversion and the conversion was found to be dependent on the flux, amount of catalyst, and initial concentration of nitrophenol. The proposed mathematical model equation represents satisfactorily the reaction and transport phenomena in flow-through catalytic membrane reactor.
\end{abstract}

\section{Introduction}

The concept of membrane reactors (MRs), combining a membrane-based separation with a catalytic chemical reaction in one unit, dates back to the 1960s [1]. Since then, MRs played an important role in improving selectivity and yielding and enhancing conversion for thermodynamically limited chemical reactions in many chemical processes of industrial importance. In recent years, many approaches have been proposed to combine membrane properties with chemical reaction in order to intensify a process. These include extractor type, distributor, and contactor type. Depending on the type of membrane reactors, the membrane performs different functions $[2,3]$.

(1) Extractor Membrane Reactors. One of the products is continuously and selectively removed from the reaction mixture by the membrane. If the reaction is limited by the thermodynamic equilibrium, the conversion can be increased by removing one of the product components, so that the equilibrium shifts towards the desired product side $[4,5]$. If the reaction rate of the undesired secondary reaction is higher than that of the primary reaction, the reaction selectivity can be significantly enhanced by removing the desired intermediate species. Particularly, the advantage of selectively removing the valuable product lies in avoiding further separation steps or reducing the separation units by increased product concentrations. Furthermore, if one of the products has inhibition effect, as in case of some fermentation, removing this product strongly improves the reactor productivity [6].

(2) Distributor Membrane Reactors. In this type of MR, one of the reactants is specifically added to the reaction mixture 
across a membrane. The membrane can act as even distributor of the limiting reactant along the reactor to prevent side reactions and as upstream separation unit to selectively dose one component from a mixture. Controlled addition of oxygen in gas-phase partial oxidation of hydrocarbons in which the intermediate product reacts more intensively with oxygen than the reactants, in order to prevent total oxidation $[7,8]$, is the main application of this category of membrane reactor.

(3) Contactor Membrane Reactors. In this configuration, the reacting species are fed at different sides of the membrane and must diffuse through the catalytic layer to react. Therefore, the role of the membrane is to provide an interfacial contact area for the reacting streams but does not perform any selective separation. The two sides of membranes are used to bring reactants into contact and if the reaction rate is fast compared to the diffusion rates of the reactants, the reaction occurs in the catalytic layer in a way that prevents mixing of reactants. Due to higher surface area of membranes, a contactor mode can provide higher contact area between two different phases. Particularly, if one phase has lower solubility in the other phase, higher surface area contact between these phases can decrease the need of higher pressure that could have been applied to lower soluble component. Gas/liquid contactors and flow-through membrane reactors are important class of membrane contactors.

In flow-through catalytic membrane reactor (FTCMR) configuration, unselective porous catalytic membrane, either inherently catalytic or being made catalytic by impregnation of nanocatalysts, is applied in dead-end mode operation. The premixed reactants are forced to pass through the catalytic membrane. The function of the membrane is to create a reaction environment with intensive contact between the reactants and catalyst with short and controlled residence times and high catalytic activity. The main drawback in classical fixed-bed reactors is that the desired conversion is mainly limited by the pore diffusion. However, if reactants can flow convectively through the catalyst sites, the resulting intensive contact between reactants and catalyst can result in a high catalytic activity $[9,10]$. Besides, this can avoid the problems derived from internal or external mass transfer resistance that may appear in a conventional fixed-bed reactor. In FTCMR, the reactants flow convectively through the membrane to catalyst sites, which in turn results in an intensive contact between the reactants and the catalyst, thereby leading to higher catalytic activity with negligible mass transport resistance. Furthermore, the introduction of convective flow can avoid undesired side reactions $[1,10]$.

Catalytic membranes (CMs), either inherently catalytic or being made catalytic by impregnation of nanocatalysts, are known for more than a decade. In spite of this fact, the development of CMs is still a major challenge. Majority of the catalytic membranes used in industries are inorganic (either ceramic or metal); for that reason, they can withstand harsh reaction conditions (high temperature, pressure, concentration, and corrosive chemicals). The main drawbacks of such CM materials are high cost and frangibility [5]. Because polymers are less expensive and more flexible than ceramics and metals, it is possible to use them in CM development instead of high cost metals and ceramics. However, majority of the polymers are only suitable for mild operation conditions. For this compensation, high reactive catalysts should be impregnated inside the polymer membrane matrix. In such cases, active catalysts can compromise the demand of higher temperature. Therefore, stabilization of active catalysts by encapsulating inside polymer membranes can help to boost and enhance the drawbacks of polymer membranes.

Metal nanoparticles (MNPs) have shown a great potential in different catalytic processes and are well known for their higher catalytic performances. Particularly, MNPs of transition metals are found to be efficient and selective catalysts for several types of catalytic reactions. This is due to higher percentage of surface atoms and associated quantum effects. However, metal nanoparticles lack chemical stability and mechanical strength. They exhibit extremely high pressure drop or head loss in fixed-bed column operation and are not found suitable for such systems [11]. Also, MNPs tend to aggregate; this phenomenon reduces their high surface area to volume ratio and subsequently reduces effectiveness. By appropriately dispersing metal nanoparticles into surface functionalized polymer membranes, many of these shortcomings can be overcome without compromising the properties of nanoparticles. Immobilizing MNPs on polymer membrane support, besides providing a mechanical strength, it offers an option to maintain their catalytic activities by preventing unnecessary growth and aggregation. Moreover, catalytic application of MNPs is the best alternative to efficiently utilize most expensive metals. Immobilization of MNPs on polymer membrane support is therefore best strategy to overcome the drawbacks of both polymers and MNPs [12]. The use of functionalized polymer membrane as a support and stabilizing media enables synthesizing nanocatalysts at the desired "point use" and will result in formation of catalytically active polymer membrane. Encapsulation of MNPs in polymers membranes offers also unique possibilities for enhancing accessibility of catalytic sites to reactants $[13,14]$.

In this research, we developed catalytic polymer membrane for liquid phase reactions by surface modification of flat sheet PES microfiltration membrane using UV-induced graft polymerization and synthesizing of stable palladium nanoparticle via intermatrix synthesis method inside surface functionalized PES membranes. The catalytic performance of the membrane was evaluated using reduction of $p$-nitrophenol (NP) as a model for liquid phase reaction.

\section{Materials and Methods}

2.1. Materials. The following chemicals and materials were used during the experiment: acrylic acid (AA), Nmethyl-2-pyrrolidone (NMP), polyvinylpyrrolidone powder (PVP, $\left.M_{w}=29,000\right)$, casting knife, acrylic acid (AA), $\mathrm{N}, \mathrm{N}^{\prime}$-methylenebisacrylamide, 4-hydroxybenzophenone, and tetra-ammine palladium(II)chloride monohydrate. All compounds have been used without any purification and solutions were prepared with deionized water.

2.2. Membrane Preparation. Flat sheet PES microfiltration membranes were prepared via nonsolvent induced phase 
separation (NIPS) using a solution containing polyethersulfone (18\% wt) as polymer and N-methyl-2-pyrrolidone (62\% wt) as solvent and polyvinylpyrrolidone (PVP 20\% wt) as a pore former. The solution was casted using a casting knife with $350 \mu \mathrm{m}$ thickness and is precipitated in a coagulation water bath at $18-20^{\circ} \mathrm{C}$.

2.3. Membrane Functionalization. Flat sheet PES microfiltration membranes were immersed for 3 minutes in $30 \mathrm{ml}$ aqueous solution of AA monomer (25 wt\%). After the immersion, samples were grafted using a simple photografting setup, containing quartz UV lamp. Exposure time was (5-20) minutes. Distance from the light source to the sample was adjusted to a minimum $6 \mathrm{~cm}$, in order to avoid a possible heat up of the membrane. After grafting, samples were washed with deionized water in order to remove unreacted monomer. Dried samples were taken for surface analysis surface using attenuated total reflection Fourier transform infrared spectroscopy (ATR-FTIR, Thermo-Nicolet Nexus)

2.4. Precursor Loading and Intermatrix Synthesis of PdNanoparticles. The synthesis of Pd-NPs inside the functionalized flat sheet PES polymer membrane matrix was carried out via intermatrix synthesis (IMS) method with procedures consisting of the following: (1) palladium salt $\left[\mathrm{Pd}\left(\mathrm{NH}_{3}\right)_{4} \mathrm{Cl}_{2}\right]$ which was loaded to the functionalized membrane which enables cation exchange between carboxylic groups of functionalized PES with $\left[\mathrm{Pd}\left(\mathrm{NH}_{3}\right)_{4}\right]^{2+}$ ions to took place and (2) subsequent chemical reduction by $0.1 \mathrm{M} \mathrm{NaBH}_{4}$ solution: the cation exchange was performed by submerging grafted membrane in to palladium precursor solution $(0.01 \mathrm{M}$ $\left.\mathrm{Pd}\left(\mathrm{NH}_{3}\right)_{4} \mathrm{Cl}_{2}\right)$ over night at room temperature. The synthesis can be summarized by the following sequential equations of ion exchange ((1) and (2)) and chemical reduction ((3) and (4)) [13]:

$$
\begin{aligned}
& \text { (1) } 2 \mathrm{R}-\mathrm{COO}^{-} \mathrm{H}^{+}+\left[\mathrm{Pd}\left(\mathrm{NH}_{3}\right)_{4}\right]^{2+} \rightarrow(\mathrm{R}- \\
& \left.\mathrm{COO}^{-}\right)_{2}\left[\mathrm{Pd}\left(\mathrm{NH}_{3}\right)_{4}\right]^{2+}+2 \mathrm{H}^{+} \\
& \text {(2) }\left(\mathrm{R}-\mathrm{COO}^{-}\right)_{2}\left[\mathrm{Pd}\left(\mathrm{NH}_{3}\right)_{4}\right]+2 \mathrm{Na}^{+} \rightarrow 2\left(\mathrm{R}-\mathrm{COO}^{-}\right) \mathrm{Na}+ \\
& {\left[\mathrm{Pd}\left(\mathrm{NH}_{3}\right)_{4}\right]^{2+}} \\
& \text { (3) }\left[\mathrm{Pd}\left(\mathrm{NH}_{3}\right)_{4}\right]^{2+}+2 \mathrm{BH}_{4}^{-}+6 \mathrm{H}_{2} \mathrm{O} \rightarrow \mathrm{Pd}^{0}+7 \mathrm{H}_{2}+ \\
& \\
& 2 \mathrm{~B}(\mathrm{OH})_{3}+4 \mathrm{NH}_{3} \\
& \text { (4) }\left[\mathrm{Pd}\left(\mathrm{NH}_{3}\right)_{4}\right]^{2+}+2 \mathrm{e}^{-} \rightarrow \mathrm{Pd}^{0}+4 \mathrm{NH}_{3}
\end{aligned}
$$

2.5. Palladium Content Measurement. The amount of palladium nanoparticle loaded to the functionalized membrane was determined by using inductively coupled plasma optical emission spectrometry (ICP-OES, Ultima 2, Horoba Jobin Yvon). $1 \mathrm{~cm}^{2}$ sample of Pd loaded membrane was dissolved in aqua regia, which is a highly corrosive mixture of acids, for two days. The acid mixture was prepared by freshly mixing concentrated nitric acid (65\%) and hydrochloric acid (35\%) in a volume ratio of $1: 3$. It was then diluted in ultra-pure water so as to analyze in ICP.

2.6. Catalytic Performance Evaluation. The catalytic performance of Pd loaded flat sheet PES membrane was evaluated by the reduction of $p$-nitrophenol to $p$-aminophenol with

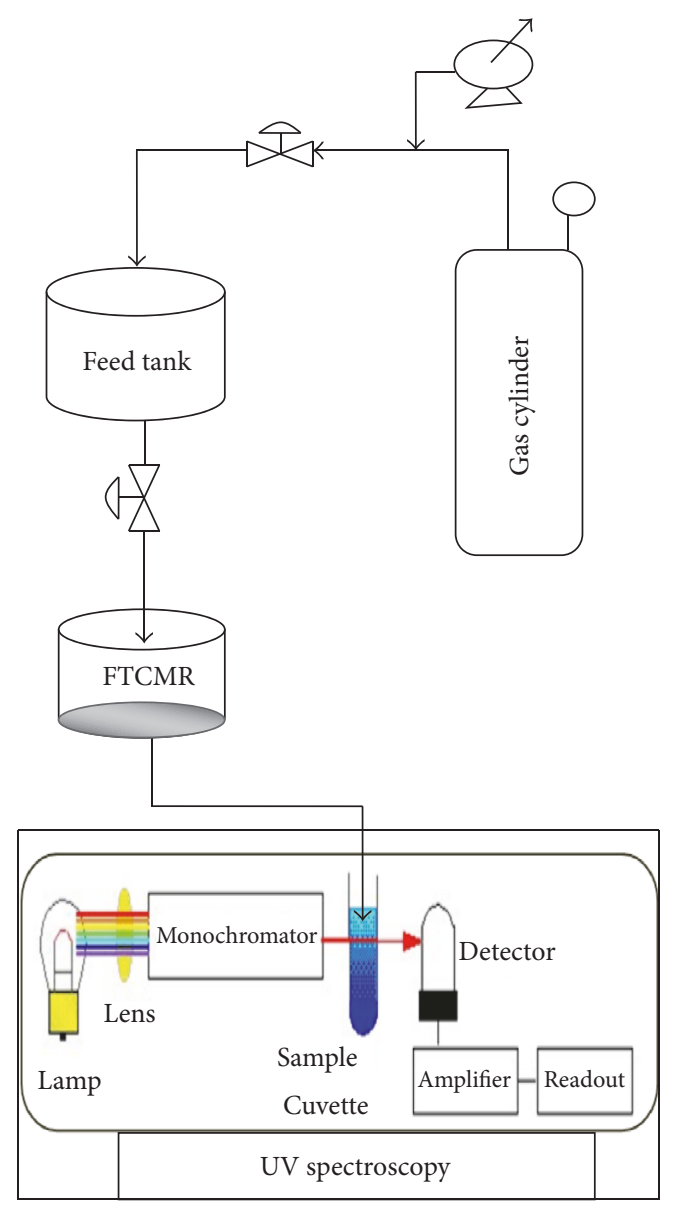

FIGURE 1: FTCMR experimental setup.

$\mathrm{NaBH}_{4}$ in FTCMR setup shown in Figure 1. The reduction of $p$-nitrophenol in the presence of nanoparticles has been frequently used previously in order to evaluate the catalytic activity of different metal nanoparticles immobilized on membranes [15-17]. In addition, this reaction has been used to test the catalytic activity of metal nanoparticles immobilized in other carrier systems like core-shell. Previous work demonstrated that $p$-nitrophenol is reduced to aminophenol only in the presence of the catalyst; no reaction takes place in the absence of the nanoparticles [15].

In FTCMR configuration shown in Figure 2, a solution containing different concentrations of a mixture of $p$ nitrophenol and $\mathrm{NaBH}_{4}$ was forced to pass through the membrane. An excess of $\mathrm{NaBH}_{4}$ was used, so that the kinetics can be assimilated to a pseudo first order in terms of concentration of $p$-nitrophenol. The progress of the reaction was monitored by measuring the concentration of $p$-nitrophenol using UV-visible spectroscopy at $(\lambda=400 \mathrm{~nm})$.

2.7. Mathematical Modeling. Convective mass transport is taking place in FTCMR, because there exists transmembrane pressure difference between the two sides of membrane, so as to enforce the reactants to pass through. In some membranes, such as nanofiltration membrane, the presence of convective flow by pressure difference enhances the diffusive driving 


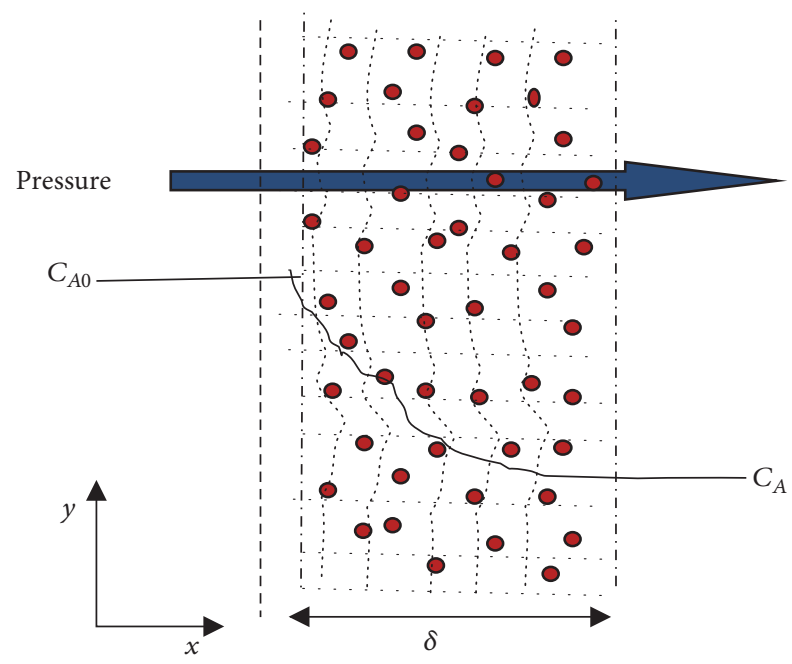

FIGURE 2: Scheme of one-dimensional mass transport across catalytic layer in flow-through membrane reactor (red particles are the catalysts, and $C_{A 0}$ and $C_{A}$ are initial and final concentration of reactant $A$, resp.).

force. Hence investigating combined effect of the diffusive and convective flows is important in surface functionalized polymer membranes. The model takes into account simultaneous transport by convective and diffusive mass flow with chemical reaction. Emin et al. [17] have clearly shown that palladium nanoparticles have been only immobilized on the grafted poly (acrylic acid) layer. Analyzing the sample using energy-dispersive X-ray spectroscopy (EDX) showed that NPs were not found deep in the support membrane. This fact is considered here in modeling FTCMR.

The following assumptions are considered [18].

(i) Reaction occurs uniformly at every position within the catalyst layer.

(ii) Transport of reactants through the catalyst layer occurs both by diffusion and by convection. However the diffusion term does not contribute much to permeate flow rate.

(iii) Chemical reaction occurs on the interface of the catalytic particles so that the diffusion inside the dens nanoparticle is negligible.

(iv) The concentration changes only across the catalytic membrane layer $(0.198 \mu \mathrm{m}$, from SEM measurement $)$ and nanoparticles are immobilized and stabilized on the grafted layer.

The differential mass transport across a reactive membrane layer with constant transport parameters through combined mass transport with chemical reaction, which is represented in Figure 2, can be described by a continuity equation for Cartesian coordinate system. For reactant species $A$ [18],

$$
\begin{aligned}
& C\left(\frac{\partial X_{A}}{\partial t}+V_{x} \frac{\partial X_{A}}{\partial x}+V_{y} \frac{\partial X_{A}}{\partial y}+V_{z} \frac{\partial X_{A}}{\partial z}\right) \\
& =C * D\left(\frac{\partial^{2} X_{A}}{\partial x^{2}}+\frac{\partial^{2} X_{A}}{\partial y^{2}}+\frac{\partial^{2} X_{A}}{\partial z^{2}}\right)+r_{A}
\end{aligned}
$$

where $C$ is the concentration, $X_{A}$ is molar fraction, $D$ is the diffusion coefficient in the membrane $\left(\mathrm{m}^{2} / \mathrm{hr}\right), r_{A}$ is rate of reaction, and $V$ is the convective velocity $(\mathrm{m} / \mathrm{hr})$ through the membrane. For steady state system with a convective flow in $x$ direction, the above equation becomes

$$
V_{x} \frac{d C_{A}}{d x}=D \frac{d^{2} C_{A}}{d x^{2}}+r_{A} .
$$

For pseudo first-order reaction, $r_{A}=-K_{\mathrm{app}} * C_{A}$, where $K_{\mathrm{app}}$ is the apparent kinetic constant and $C_{A}$ is the concentration of reactant $A$. Substitution of rate of reaction to (2) gives

$$
D \frac{d^{2} C_{A}}{d x^{2}}-V_{x} \frac{d C_{A}}{d x}-K_{\text {app }} * C_{A}=0 .
$$

Defining and introducing the dimensionless length epsilon $(\varepsilon)=x / \delta$, whose value varies from 0 to 1 , where $\delta$ is catalytic membrane layer $(0.198 \mu \mathrm{m})$ and $x$ is the catalytic layer at any distance, substituting to (3) gives

$$
\frac{d^{2} C_{A}}{d \varepsilon^{2}}-\frac{V * \delta}{D} * \frac{d C_{A}}{d \varepsilon}-\frac{K_{\mathrm{app}} \delta^{2}}{D} C_{A}=0
$$

Two dimensionless groups' Peclet number $\left(P_{e}\right)$ and reaction modulus $\left(\emptyset^{2}\right)$ are defined and inserted to (4), where

$$
\begin{aligned}
& P_{e}=\frac{V * \delta}{D} \\
& \emptyset^{2}=\frac{K_{\mathrm{app}} \delta^{2}}{D} .
\end{aligned}
$$

The diffusion coefficient was predicted based on the variation of the actual measurement taken from the filtration unit and a model prediction that ignores the diffusion term (as if the entire process was controlled by the convective flow). The solution of (4) is

$$
\begin{aligned}
& \frac{C_{A}}{C_{A 0}}=\exp \left[\frac{P e \varepsilon}{2}\right] \\
& \cdot\left[\frac{\sinh (\varphi(1-\varepsilon)) * P e / 2+\varphi \cosh [\varphi(1-\varepsilon)]}{(P e / 2) \sinh \varphi+\varphi \cosh \varphi}\right],
\end{aligned}
$$

where $\varphi=\sqrt{\left(P_{e}^{2} / 4+\emptyset^{2}\right)}$.

We can predict the concentration distribution at the end of the membrane $(\varepsilon=1)$, as function of initial concentration $\left(C_{A 0}\right)$, Peclet number, and reaction modules with the following equation [18]:

$$
\frac{C_{A}}{C_{A 0}}=\frac{\varphi * \exp (P e / 2)}{(P e / 2) \sinh \varphi+\varphi \cosh \varphi} .
$$

\section{Results and Discussion}

3.1. Membrane Surface Functionalization. Both unmodified PES and the UV-induced modified flat sheet membranes were characterized by ATR-FTIR. Figure 3 shows the spectra of the unmodified and modified membranes with AA monomer. As 


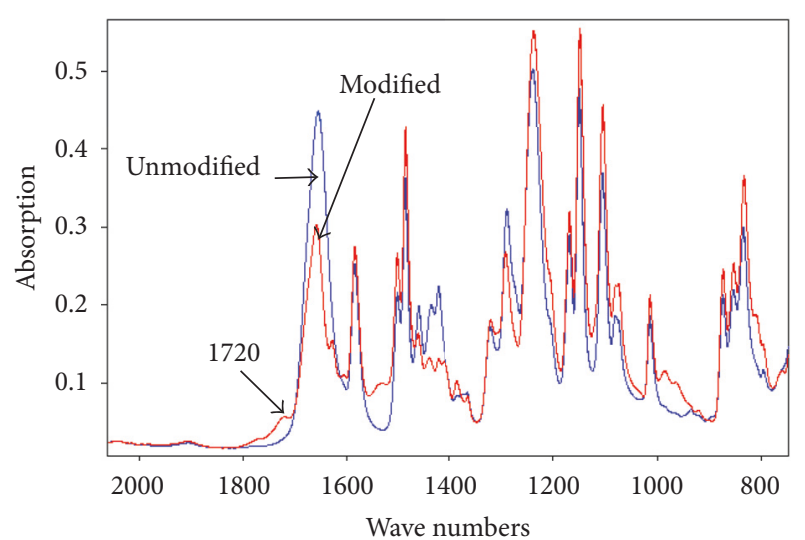

FIgUre 3: The ATR-FTIR spectra of unmodified and modified PES flat sheet membranes using UV grafting of AA (25 wt\%) at $20 \mathrm{~min}$ UV batch irradiation time.

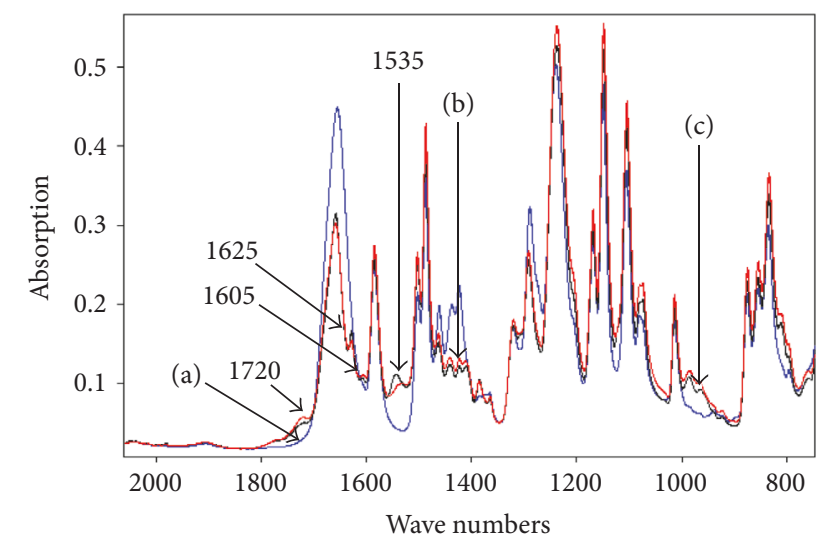

FIGURE 4: The ATR-FTIR spectra of the (a) unmodified flat sheet PES membrane and modified membranes using UV-induced grafting with (25 wt \% AA); (b) 20; and (c) 15 minute UV irradiation time, respectively.

can be seen, UV-induced grafted membranes exhibit different ATR-FTIR spectra than the unmodified one. In addition to the typical PES bands of the unmodified membrane, the IR spectra of modified membrane show additional peak at $1720 \mathrm{~cm}^{-1}$, which corresponds to the carbonyl $(\mathrm{C}=\mathrm{O})$ group bands of $\mathrm{COOH}$, which indicates the existence of poly(acrylic acid) chains [19] and assured that the monomer is successfully polymerized on the substrate PES. Also, with UV modification, some original absorbance peak intensity is decreased that can be contributed to increase coverage of the PES surface by poly(acrylic acid).

Apart from this, as can be seen from FTIR spectra of modified membrane in Figure 4, the intensity of the new peak at $1720 \mathrm{~cm}^{-1}$ increases with photografting reaction time which corresponds to the energy received during graft polymerization. The more the energy received by the monomer, the higher the degree of modification. In addition to the new absorption peak corresponding to the carbonyl group $(\mathrm{C}=\mathrm{O})$ of $\mathrm{COOH}$, there are also other new small absorbance peaks appearing at 1625,1605 , and $1535 \mathrm{~cm}^{-1}$ for the modified

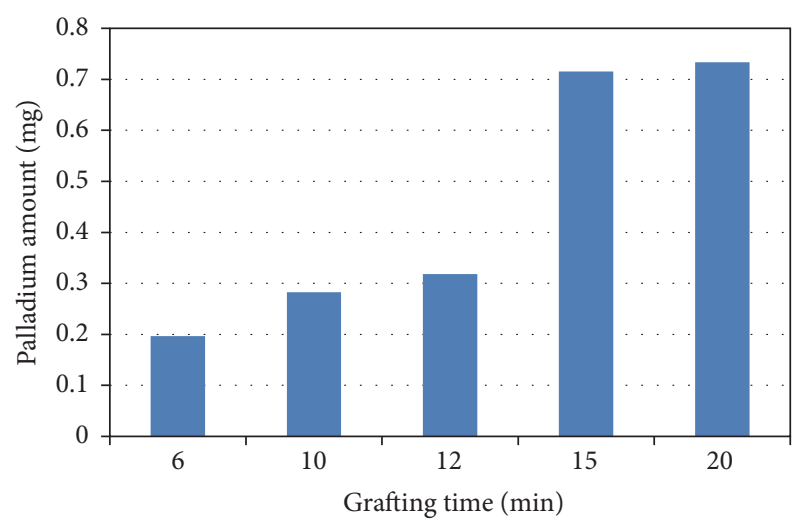

FIgURE 5: Palladium amount per membrane $\left(15.2 \mathrm{~cm}^{2}\right)$ versus grafting time.

membranes. The small absorbance peak for the AA-modified membranes at these regions attributed to the presence of additives such as PVP in the original casting solution and cross linker in the monomer solution, as reported by Rahimpour [20] and Bernstein et al. [21]. Also, the disappearance of the original peaks at $1640-1680 \mathrm{~cm}^{-1}$ for the modified membranes indicates that the modification was successful.

Membranes grafted at different times were used to synthesize Pd nanoparticle. ICP analysis in Figure 5 showed that the weight of Pd loading is increasing with grafting time (energy received). These data are in agreement with expected and FTIR results. At higher energy, the intensity of the modified functional group was stronger which can lead to better cation exchange with Pd precursor and thus higher Pd amount from the reduction.

3.2. Catalytic Performance Evaluation. The effect of the nitrophenol concentration in the feed on the conversion was investigated using different feed concentrations and the same amount of Pd at a room temperature. A closer look at Figure 6 clearly shows the effect of initial $p$-NP concentration on conversion. The conversion is higher for the lower $p$ $\mathrm{NP}$ initial concentration. In all of initial $p$-NP concentration ranges (i.e., $0.033-0.128 \mathrm{mM}$ ), the same trend was obtained, which strongly indicates that reaction on Pd nanoparticle is highly active dependant surface. For the same catalyst loading and permeate flux (i.e., approximately the same residence time and applied pressure within a membrane), the catalytic activity of membranes with lower initial concentration was higher than that of higher initial $p$-NP concentration.

Furthermore, the inverse proportionality of $p$-NP conversion with permeate flux confirmed that our Pd loaded membranes were not mass transfer limited; rather it was reaction limited. If membranes were mass transfer limited, we would not observe a decrease of conversion with increased fluxes. As the applied pressure in flow-through mode enforces reactants to have an intensive contact with catalyst, the reaction at the surface of the catalyst is the main limitation to such system. As a result of increasing pressure (flux), reactants permeate through the membrane without reacting; 


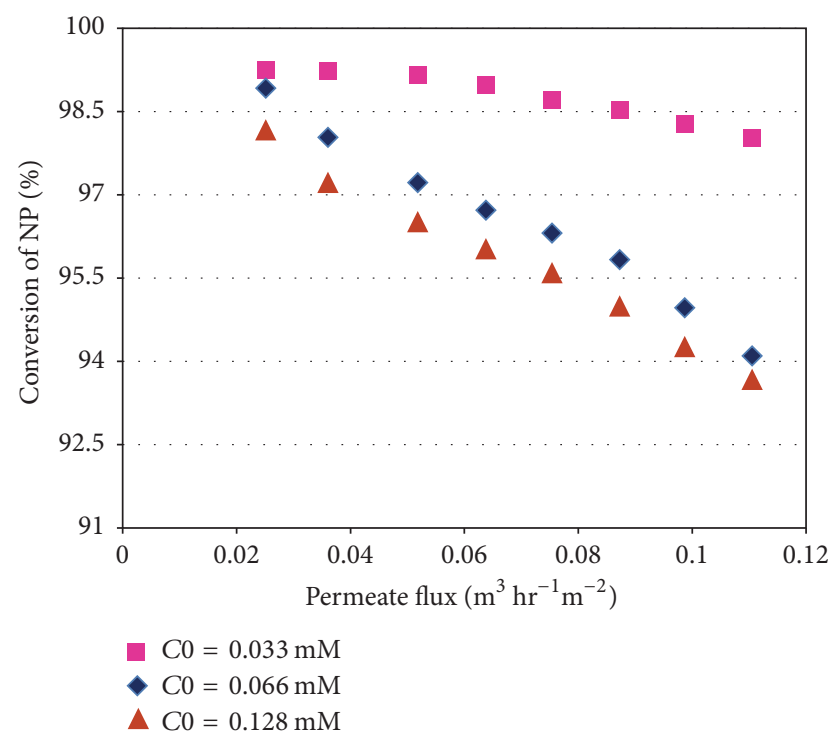

Figure 6: Conversion of nitrophenol (NP) in Pd loaded PES membrane versus flux for single pass in dead-end mode of filtration $(0.283 \mathrm{mg}$ of palladium).

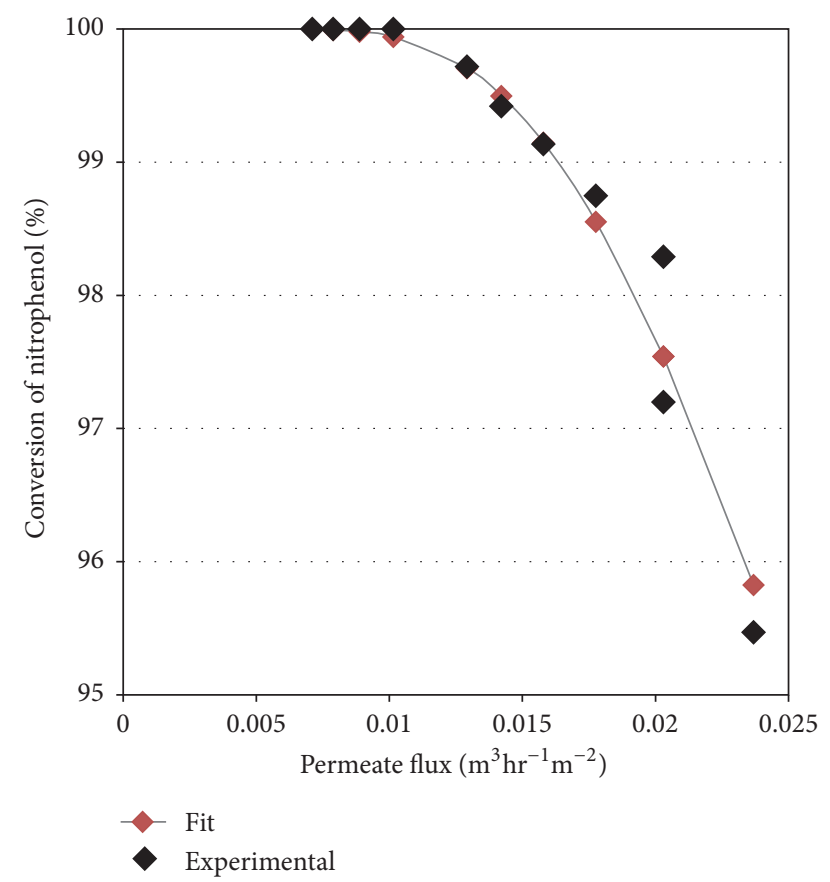

FIGURE 7: Plot of $p$-NP conversion versus flux. The curve (with red diamond) represents a first-order reaction model with a rate constant $\left(K_{\text {app }}\right)$ of $300 \mathrm{hr}^{-1}$. Feed conditions: [ $p$-nitrophenol] = $0.514 \mathrm{mM},\left[\mathrm{NaBH}_{4}\right]=14.38 \mathrm{mM}, \mathrm{Pd}=0.733 \mathrm{mg}$, and catalytic layer $=0.198 \mu \mathrm{m}$.

hence the conversion decreases. Similar results were reported by Dotzauer et al. [22] and Crock et al. [23].

Figure 7 shows the experimental plot points and model predictions according to the model equation (7) developed and it confirms well to a simple first-order kinetic model of the reaction. The proposed mathematical model equation

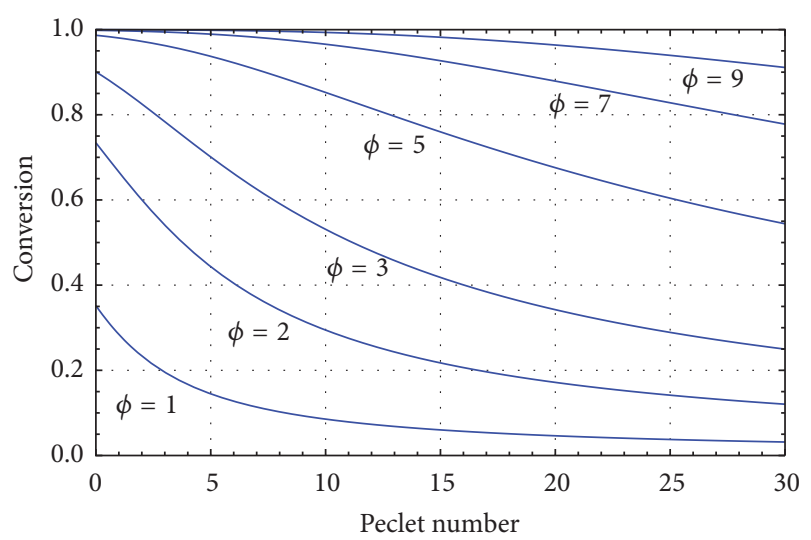

FIGURE 8: Simulation of conversion versus convective flow (Peclet number) at different values of reaction modulus.

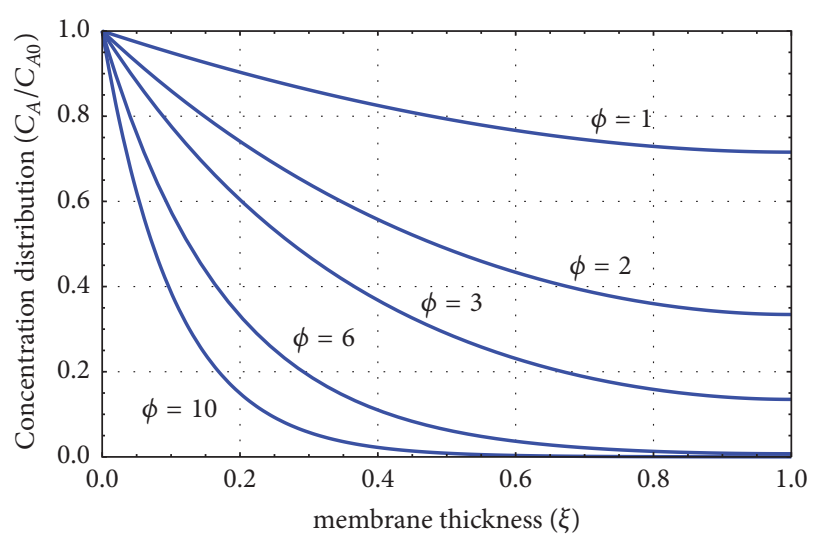

FIGURE 9: Simulation of concentration distribution across the catalytic layer at different values of reaction modulus as function of membrane thickness.

represents satisfactorily the reaction and transport phenomena in flow-through catalytic membrane reactor. From the same figure, it can be concluded that both convective and diffusive transport through the catalytic membrane layer contributed to the catalytic activity of the nanoparticle.

In order to understand better and check the effect of different parameters, simulations of the FTCMR were performed using Wolfram Mathematica 7, at different process parameters such as Peclet number $(P e)$, reaction modulus $\left(\emptyset^{2}\right)$, catalytic membrane layer thickness $(\delta)$, and concentrations.

Simulation results of Figures 8 and 9 showed the effect of different process parameters such as Peclet number $(\mathrm{Pe})$, reaction modulus $\left(\emptyset^{2}\right)$, and catalytic membrane layer thickness $(\delta)$ on the outlet concentrations of the reactant.

\section{Conclusion}

In this work, surface modification of polyethersulfone membrane by UV-assisted grafting polymerization of acrylic 
acid has been successfully done. Catalytically active and efficient Pd nanoparticle has been synthesized via intermatrix synthesis. As a model for liquid phase reaction, its catalytic performance was investigated by the reduction of aqueous $p$ nitrophenol to $p$-aminophenol with sodium borohydride as reductant. The catalytic activity of Pd embedded membrane was shown to be directly proportional to the palladium content in the nanocomposite. The catalytic activity of flowthrough reactor for reduction of nitrophenol outperformed the batch mode of operation, as it was demonstrated by conversion comparison at the same initial nitrophenol concentration and weight of catalyst. This was attributed to the convective flow of reactants directly to the catalyst sites which can provide an intensive contact. An important asset in application of catalyst embedded membrane is the possibility of varying the flux to control the conversion. At lower and moderate range of fluxes, a complete conversion was achieved in FTCMR, but an increase in the flux decreased the conversion, because of insufficient contact time. The effect of initial nitrophenol concentration at the same flux and catalyst has been investigated. In all concentration ranges taken, a lower initial concentration had higher conversion, as higher concentration poses surface coverage of the catalyst. Further investigation of $p$-nitrophenol reduction reactions related to porosity of the grafted layer has to be done. The proposed mathematical model equation represents satisfactorily the reaction and transport phenomena in flow-through catalytic membrane reactor.

\section{Conflicts of Interest}

The authors would like to declare that there are no conflicts of interest regarding the publication of this paper.

\section{References}

[1] A. Julbe, D. Farrusseng, and C. Guizard, "Porous ceramic membranes for catalytic reactors - Overview and new ideas," Journal of Membrane Science, vol. 181, no. 1, pp. 3-20, 2001.

[2] T. Westermann, Flow-Through Membrane Microreactor for Intensified Heterogeneous Catalysis, 2009.

[3] T. Westermann and T. Melin, "Flow-through catalytic membrane reactors-principles and applications," Chemical Engineering and Processing: Process Intensification, vol. 48, no. 1, pp. 17-28, 2009.

[4] R. Dittmeyer, V. Höllein, and K. Daub, "Membrane reactors for hydrogenation and dehydrogenation processes based on supported palladium," Journal of Molecular Catalysis A: Chemical, vol. 173, no. 1-2, pp. 135-184, 2001.

[5] S. S. Ozdemir, M. G. Buonomenna, and E. Drioli, "Catalytic polymeric membranes: Preparation and application," Applied Catalysis A: General, vol. 307, no. 2, pp. 167-183, 2006.

[6] K. K. Sirkar, P. V. Shanbhag, and A. S. Kovvali, "Membrane in a reactor: A functional perspective," Industrial \& Engineering Chemistry Research, vol. 38, no. 10, pp. 3715-3737, 1999.

[7] Y. Zhang, K. Su, F. Zeng, W. Ding, and X. Lu, "A novel tubular oxygen-permeable membrane reactor for partial oxidation of $\mathrm{CH}_{4}$ in coke oven gas to syngas," International Journal of Hydrogen Energy, vol. 38, no. 21, pp. 8783-8789, 2013.
[8] M. A. Al-Juaied, D. Lafarga, and A. Varma, "Ethylene epoxidation in a catalytic packed-bed membrane reactor: Experiments and model," Chemical Engineering Science, vol. 56, no. 2, pp. 395-402, 2001.

[9] M. Pera-Titus, M. Fridmann, N. Guilhaume, and K. Fiaty, "Modelling nitrate reduction in a flow-through catalytic membrane contactor: Role of pore confining effects on water viscosity," Journal of Membrane Science, vol. 401-402, pp. 204-216, 2012.

[10] E. Nagy, "Mass transfer through a convection flow catalytic membrane layer with dispersed nanometer-sized catalyst," Industrial \& Engineering Chemistry Research, vol. 49, no. 3, pp. 1057-1062, 2010.

[11] V. V. Pushkarev, Z. Zhu, K. An, A. Hervier, and G. A. Somorjai, "Monodisperse metal nanoparticle catalysts: Synthesis, characterizations, and molecular studies under reaction conditions," Topics in Catalysis, vol. 55, no. 19-20, pp. 1257-1275, 2012.

[12] K. Na, Q. Zhang, and G. A. Somorjai, "Colloidal Metal Nanocatalysts: Synthesis, Characterization, and Catalytic Applications," Journal of Cluster Science, vol. 25, no. 1, pp. 83-114, 2014.

[13] P. Ruiz, M. Muñoz, J. MacAnás, C. Turta, D. Prodius, and D. N. Muraviev, "Intermatrix synthesis of polymer stabilized inorganic nanocatalyst with maximum accessibility for reactants," Dalton Transactions, vol. 39, no. 7, pp. 1751-1757, 2010.

[14] J. Bastos-Arrieta, A. Shafir, A. Alonso, M. Muñoz, J. MacAnás, and D. N. Muraviev, "Donnan exclusion driven intermatrix synthesis of reusable polymer stabilized palladium nanocatalysts," Catalysis Today, vol. 193, no. 1, pp. 207-212, 2012.

[15] J. Macanás, L. Ouyang, M. Bruening, M. Muñoz, J. Remigy, and J. Lahitte, "Development of polymeric hollow fiber membranes containing catalytic metal nanoparticles," Catalysis Today, vol. 156, no. 3-4, pp. 181-186, 2010.

[16] L. Ouyang, D. M. Dotzauer, S. R. Hogg, J. MacAnás, J.-F. Lahitte, and M. L. Bruening, "Catalytic hollow fiber membranes prepared using layer-by-layer adsorption of polyelectrolytes and metal nanoparticles," Catalysis Today, vol. 156, no. 3-4, pp. 100$106,2010$.

[17] C. Emin, J.-C. Remigy, and J.-F. Lahitte, "Influence of UV grafting conditions and gel formation on the loading and stabilization of palladium nanoparticles in photografted polyethersulfone membrane for catalytic reactions," Journal of Membrane Science, vol. 455, pp. 55-63, 2014.

[18] C. Endalkachew and J.-F. Lahitte, Development of Gas/Liquid Catalytic Membrane Reactor, University of Zaragoza Library Online Thesis Catalog, 2014.

[19] B. Deng, J. Li, Z. Hou et al., "Microfiltration membranes prepared from polyethersulfone powder grafted with acrylic acid by simultaneous irradiation and their $\mathrm{pH}$ dependence," Radiation Physics and Chemistry, vol. 77, no. 7, pp. 898-906, 2008.

[20] A. Rahimpour, "UV photo-grafting of hydrophilic monomers onto the surface of nano-porous PES membranes for improving surface properties," Desalination, vol. 265, no. 1-3, pp. 93-101, 2011.

[21] R. Bernstein, E. Antón, and M. Ulbricht, "UV-photo graft functionalization of polyethersulfone membrane with strong polyelectrolyte hydrogel and its application for nanofiltration," ACS Applied Materials \& Interfaces, vol. 4, no. 7, pp. 3438-3446, 2012. 
[22] D. M. Dotzauer, J. Dai, L. Sun, and M. L. Bruening, "Catalytic membranes prepared using layer-by-layer adsorption of polyelectrolyte/metal nanoparticle films in porous supports," Nano Letters, vol. 6, no. 10, pp. 2268-2272, 2006.

[23] C. A. Crock, A. R. Rogensues, W. Shan, and V. V. Tarabara, "Polymer nanocomposites with graphene-based hierarchical fillers as materials for multifunctional water treatment membranes," Water Research, vol. 47, no. 12, pp. 3984-3996, 2013. 


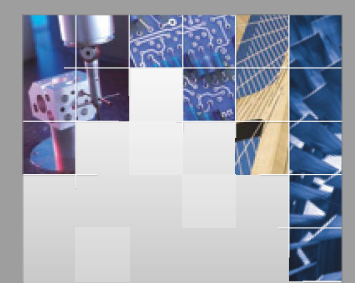

\section{Enfincering}
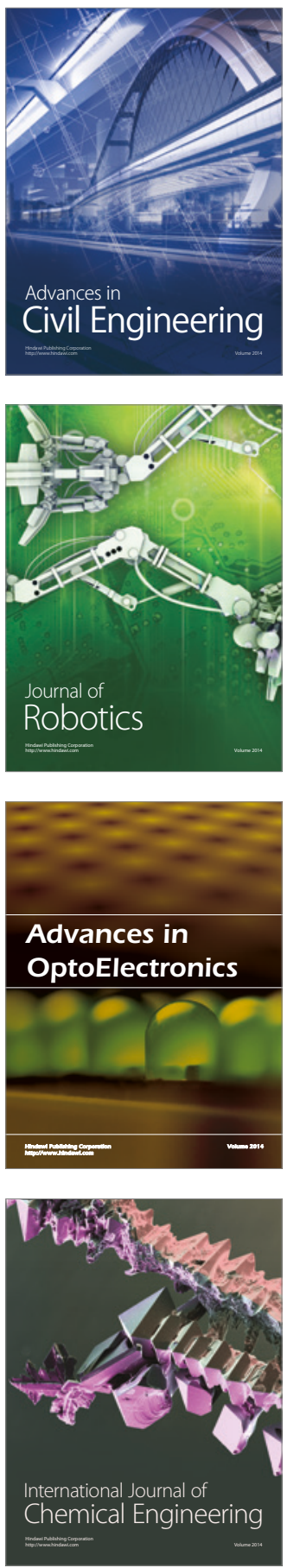

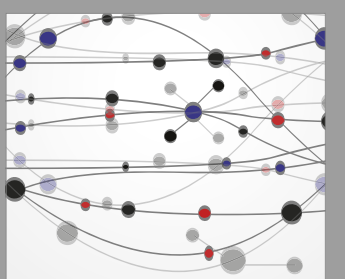

The Scientific World Journal

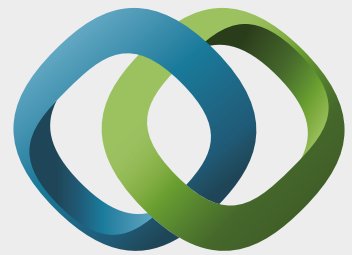

\section{Hindawi}

Submit your manuscripts at

https://www.hindawi.com
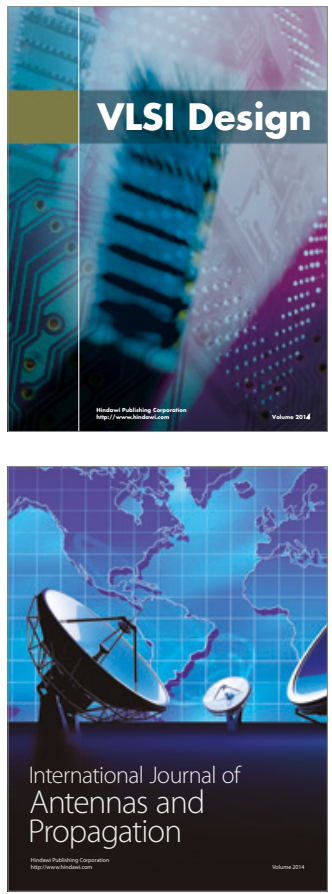

\section{Rotating}

Machinery
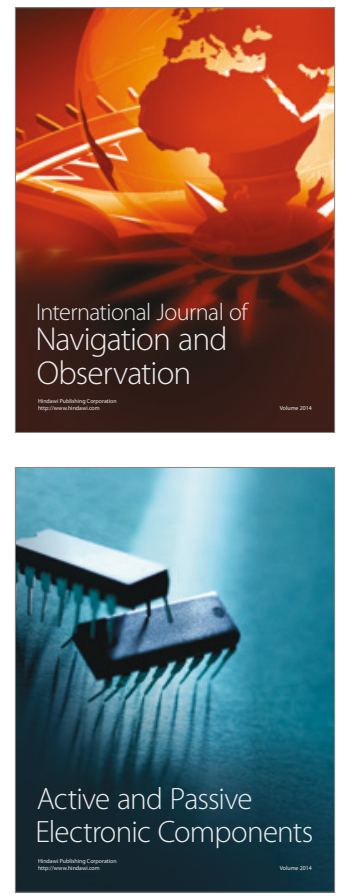
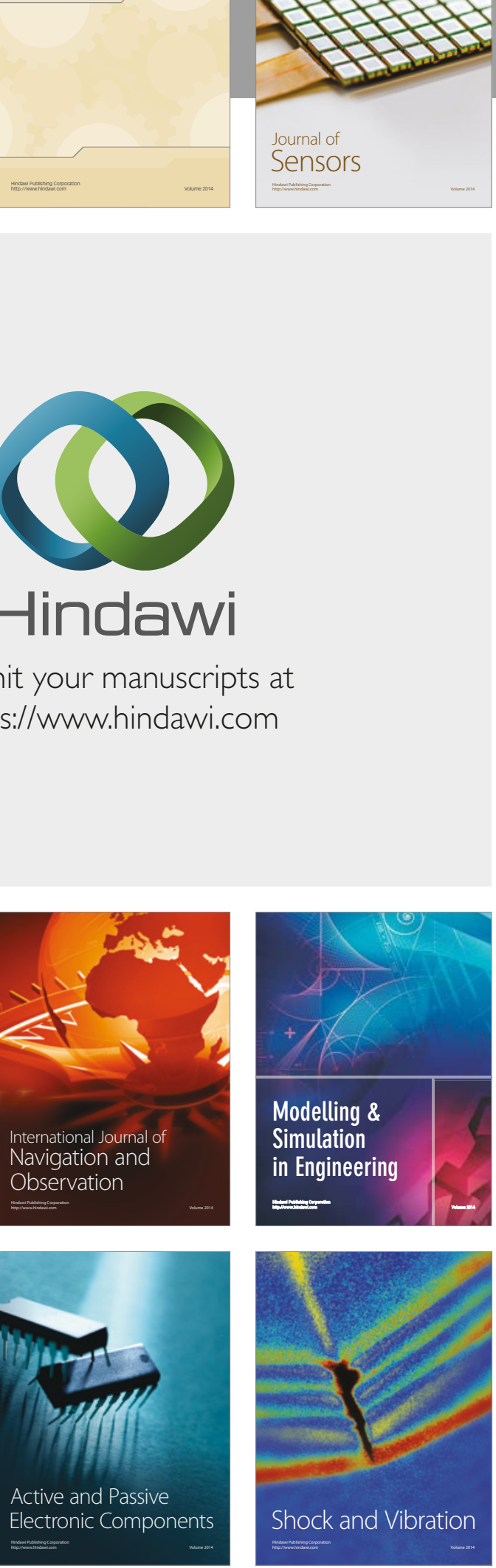
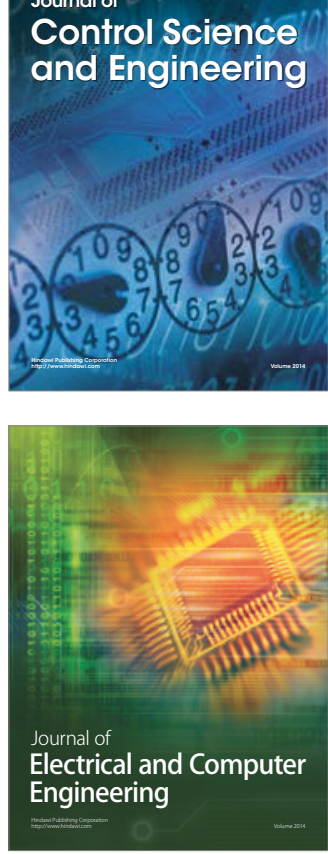

Distributed

Journal of

Control Science

and Engineering
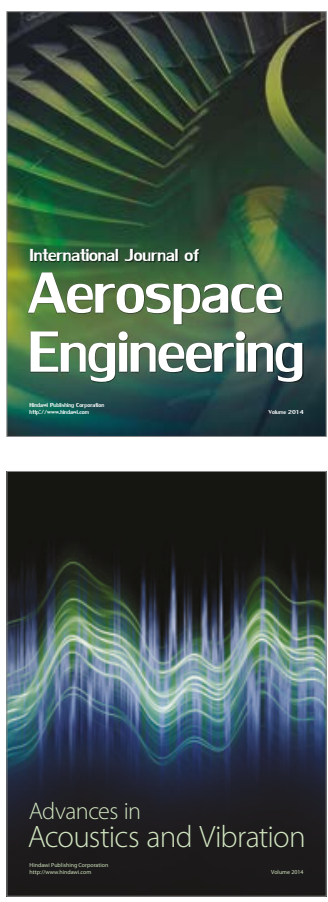

Sensor Networks 